\title{
Proposed Method for Evaluating the Relevance of Publications by Faculty Members from Tel-Hai Academic College Compared to the Academic Status of Full Professors in the Same Field in Israeli Research Universities
}

\author{
Gad Degani ${ }^{1,2}$ \\ ${ }^{1}$ Faculty of Science and Technology, Tel-Hai Academic College, Tel-Hai, Israel \\ ${ }^{2}$ MIGAL-Galilee Research Institute, Kiryat Shmona, Israel \\ Email: gad@MIGAL.org.il
}

Received 13 July 2015; accepted 4 September 2015; published 8 September 2015

Copyright (C) 2015 by author and Scientific Research Publishing Inc.

This work is licensed under the Creative Commons Attribution International License (CC BY).

http://creativecommons.org/licenses/by/4.0/

(c) (i) Open Access

\section{Abstract}

This study proposed a method using publication downloads from Research Gate (RG) and Google Scholar (GS)to evaluate scientists based on publications they made in the Faculty of Science, Environment and Community at Tel-Hai Academic College and MIGAL-Galilee Research Institute to the status of full professors in the same field in Israeli research universities. The results show that in evaluating the mean publication downloads from March 15-April 26, 2015 by full professors from Israeli universities and from Tel-Hai Academic College and MIGAL, differences exist between the average of all parameters (number of publications and citations) in the different fields of research, such as organic chemistry, medicine and biochemistry, animal science and the environment. In the different parameters used for evaluating the faculty members and their downloads, the relevance of publications during the period examined might be seen.

\section{Keywords}

Evaluation, Professors, Publication Downloads, Suggested Methods, Universities 


\section{Introduction}

The evaluation of academic faculty members in universities or academic colleges [1] is very difficult, and the publication of scientific works is one of the most important methods. The relevance for the development of satisfactory work is another problem due the fact that differences exist in the interests and variation of areas in different fields of science [2]. Different methods are developed by evaluating the list of publications and journal publications on the Internet, so it is much easier to compare fields of science and evaluate scientific work. Academic evaluation can be controversial, and many aspects and purposes are involved [2] [3]. The percentage of high academic achievements, or the number and the quality of publications, is becoming increasingly more important. However, there is agreed-upon way of evaluating the importance of a publication and the relevance of a scientist's data to other scientists all over the world.

This paper aims at evaluating faculty members/scientists who have worked during their entire academic career at Tel-Hai Academic College based on information found on the Internet that is open to everyone in order to examine and the relevance of publications and the publication downloads level of academic members from TelHai Academic College compared to full professors from Israeli universities in the same fields. Data were collected only from results found in a search carried out on Research Gate (RG) [4].

\section{Methods}

This study used various Internet sites that were easy to follow. The Internet system was examined in publication downloads during the period March 15-April 19, 2015 from Research Gate (RG) [4] and Google Scholar [5]. The comparison between Tel-Hai Academic College and full professors from the universities were made in the same area during the same activity period. The significance of the differences between group means of the number of publications, citations and impact factors was determined using a one-way analysis of variance (ANOVA), followed by a posteriori T-test using SPSS 17.0 software. Differences were considered statistically significant at $P<$ 0.05 .

\section{Results}

The evaluation of mean publication downloads using Research Gate (RG) and Google Scholar (GS) during the period March15-April 19, 2015 by full professors from universities in Israel is presented in Figure 1 and Figure 2. Table 1 shows that differences exist between the average of all parameters (number of publications and citations) in the different fields of study. Significant differences exist between full professors (Figure 1 and Figure 2) from Israeli universities and those from Tel-Hai Academic College (Figure 3). Significant differences also exist between mean publication downloads of full professors compared to associate professors, senior lecturers and lecturers (see Figures 4-6).

The results of the current study did not show differences in publication downloads between fields of research: Medicine Biotechnology, Chemistry, Environment, Animal Science or Plant Science and Biotechnology. The highest number of publication downloads was found for professors from Tel-Hai Academic College in the area

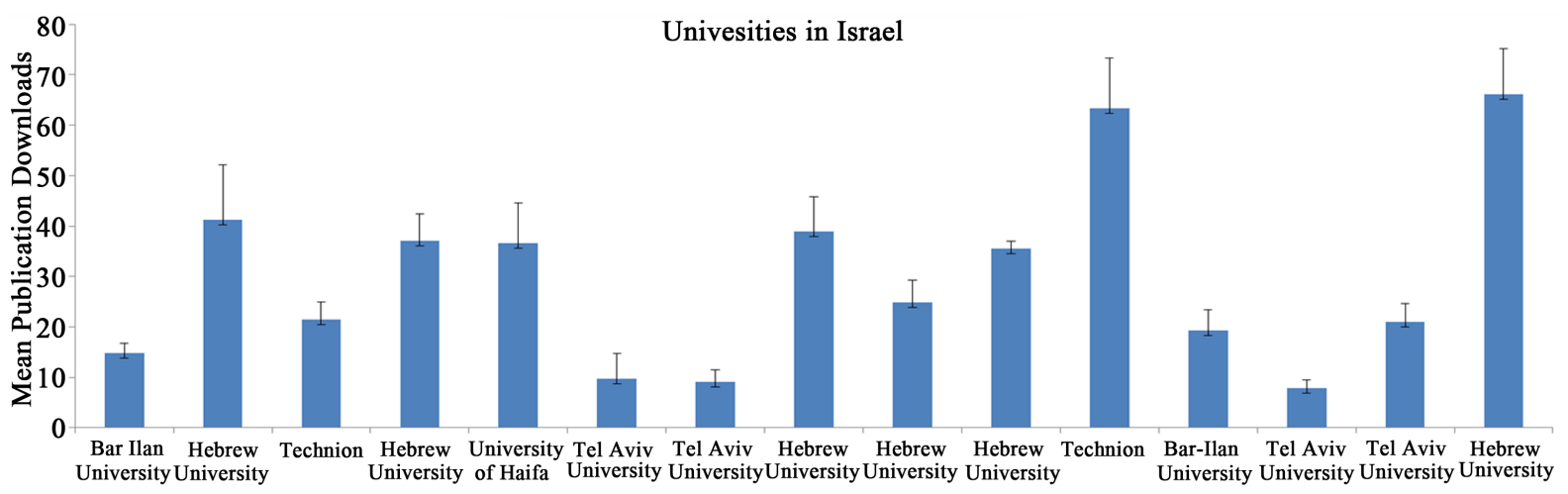

Figure 1. The mean \pm SD of publication downloads from March 15-April 26, 2015 by full professors from Israeli universities. There are significant differences between professors (ANOVA $P<0.01$ ) from Israeli universities. 


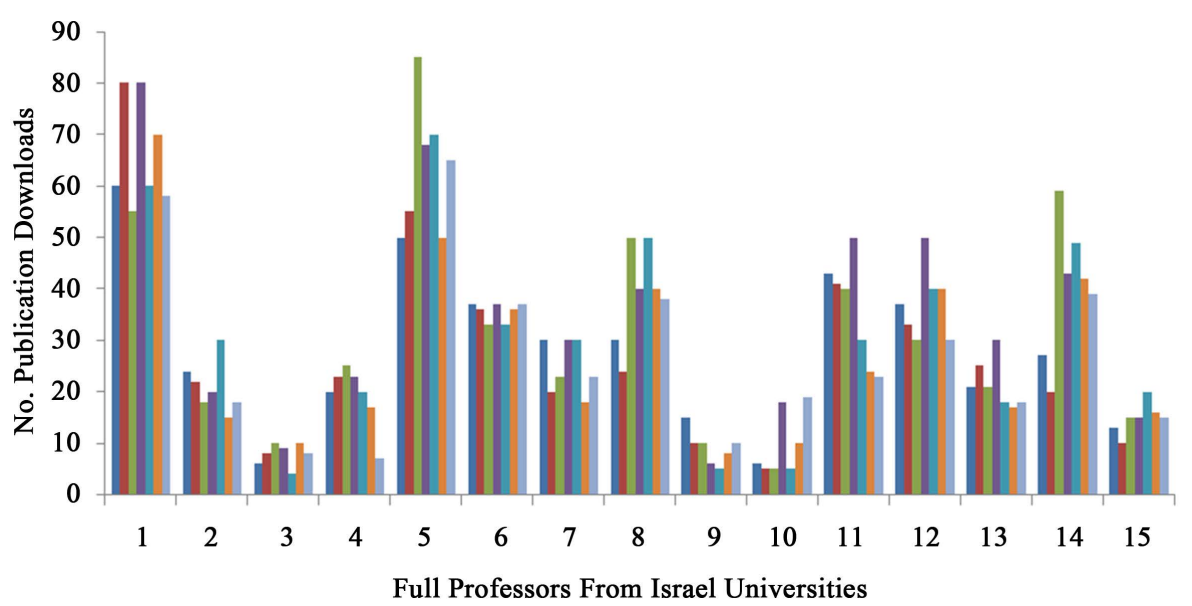

Figure 2. Downloads from March 15-April 19, 2015 by professors from Israeli universities from different fields of research (Medicine Biotechnology, Chemistry, Environment, Animal Science and Animal Biotechnology, Microbiology and Biotechnology and Nutrition). $\mathrm{H}=$ Hebrew University, $\mathrm{TU}=$ Tel Aviv University, B = Bar-Ilan University, $\mathrm{T}=$ Technion-Israel Institute of Technology, $\mathrm{H}=$ University of Haifa. $\mathrm{M}=$ Medicine, $\mathrm{E}=$ Environment, $\mathrm{A}=$ Animal Science, $\mathrm{N}=\mathrm{Nutrition}$. $1-$ H-M, 2-TU-M, 3-TU-M, 4-B-M, 5-T-M, 6-H-E, 7-H-M, 8-H-A, 9-T-A, 10-T-A, 11-H-E, 12-H-A, 13T-A, $14-\mathrm{H}-\mathrm{B}, 15-\mathrm{B}-\mathrm{A}$.

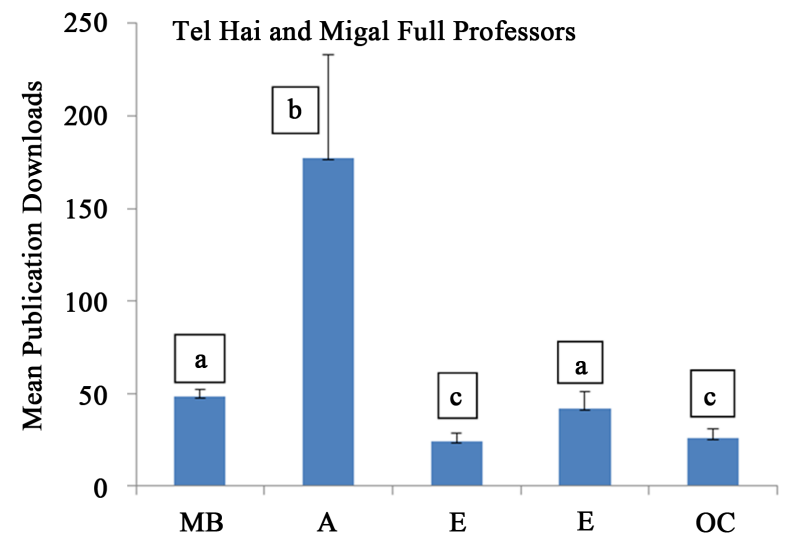

Figure 3. The mean \pm SD of publication downloads from March 15-April 19, 2015 by full professors from Tel-Hai Academic College and MIGAL. Different letters represent significance differences (t-test, $P<0.05$ ) between the various fields of research. ANOVA, $P<0.01$. Microbiology (MB), Animal Science (A), Environment (E), Organic Chemistry (OC).

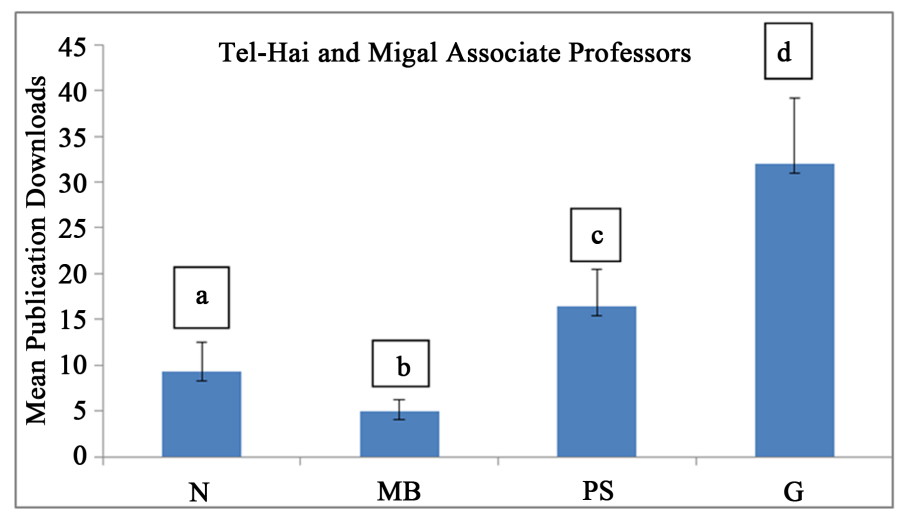

Figure 4. The mean \pm SD of publication downloads from March 15-April 19, 2015 by associate professors from Tel-Hai Academic College and MIGAL. Different letters represent significance differences (t-test, $P<0.05$ ) between the various fields of research. ANOVA, $P<0.01$. Nutrition (N), Microbiology (MB), Plant Science (PS), Genetics (G). 
Tel-Hai and Migal Seniors Lectures

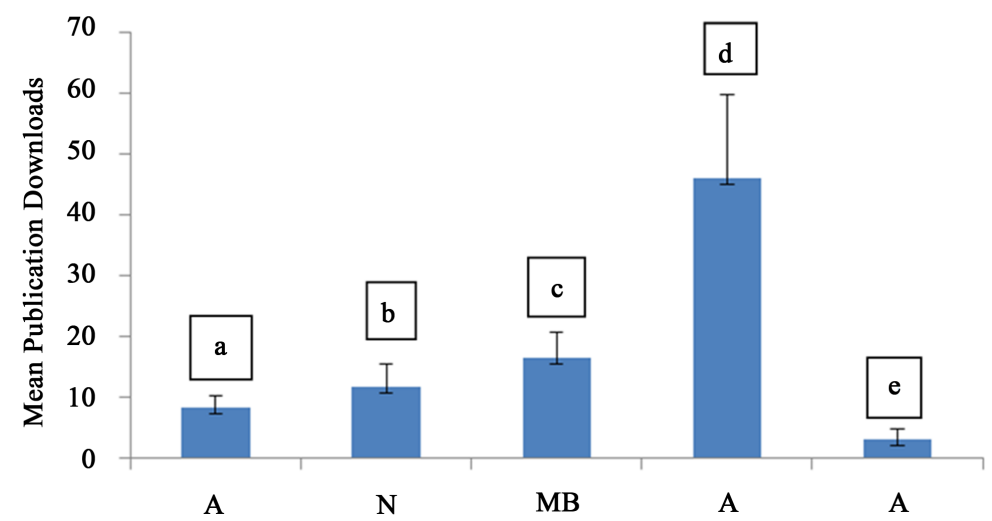

Figure 5. The mean \pm SD of publication downloads from March 15-April 19, 2015 by senior lectures from Tel-Hai Academic College and MIGAL. Different letters represent significance differences (t-test, $P<0.05$ ) between the various fields of research. ANOVA, $P<0.05$. Animal Science (A), Nutrition (N), Microbiology (MB).

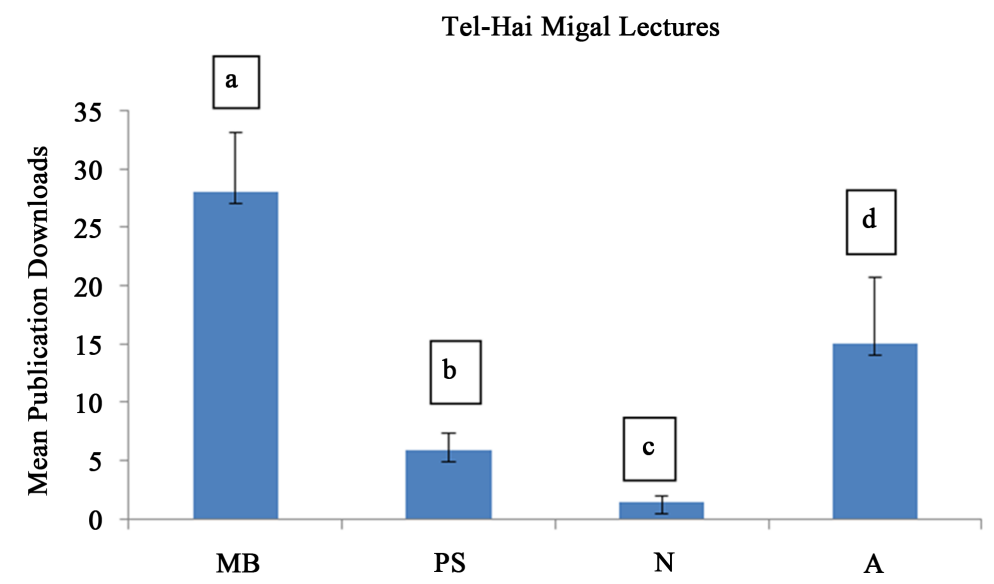

Figure 6. The mean \pm SD of publication downloads from March 15-April 19, 2015 by lecturers from Tel-Hai Academic College and MIGAL. Different letters represent significance differences (t-test, $P<0.05$ ) between the various fields of research. ANOVA, $P<0.01$. Nutrition (N), Microbiology (MB), Plant Science (PS) and Animal Science (A).

of Animal Science and the lowest was for lecturers in the area of Plant Science and Biotechnology (Figure 7). The variation in the fields of study is high (Figure 7).

The evaluation of faculty members from Tel-Hai Academic College and MIGAL by citations during the years 2004 to 2014 in the various research fields using Google Scholar (GS) is presented in Table 1. The highest number of citations was found in the area of Animal Science, then Environment Science followed by Economy, and there were significant differences according to the F-test $(P<0.05)$ (Table 1$)$. Forsenior lecturers, the number of citations by faculty members from Tel-Hai Academic College was significantly higher in the area of Animal Physiology (F-test, $P<0.05$ ) (Table 1).

\section{Discussion}

This study shows that the number of downloads is an important parameter presenting interesting results. This parameter is not affected by the degree of the faculty members at Tel-Hai Academic College and might not affect that of other faculty members in various Israel universities. The differences between faculty members of different degrees (lecturer, senior lecturer, associate professor and professor) are significant. This seems to be in agreement with a comparison made on October 9, 2014 based on data collected from Research Gate (RG) and Academic Microsoft (AM) between professors from Tel-Hai Academic College and professions from Israel 


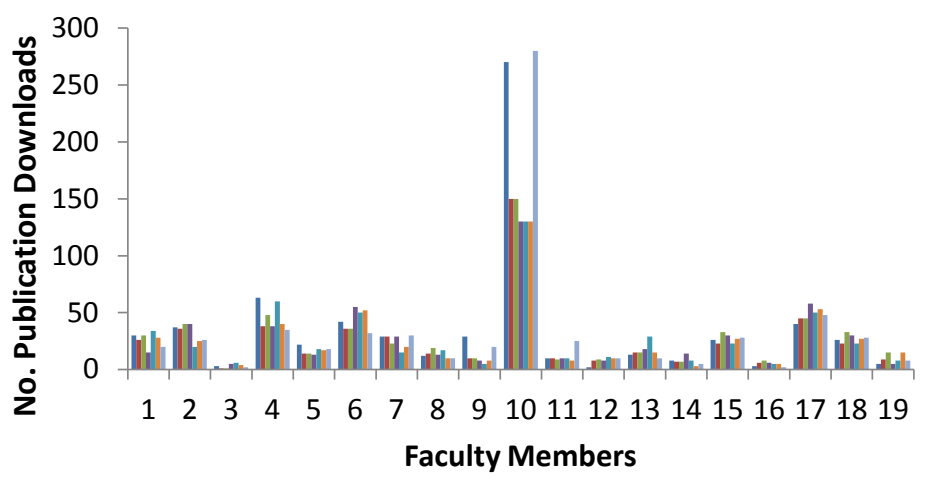

Figure 7. Publication downloads from March 15-April 26, 2015 by faculty members of various degrees from Tel-Hai Academic College and MIGAL: Medicine Biotechnology (M), Organic Chemistry (OC), Environment (E), Animal Science (A), Plant Science (PS), Microbiology (MB) and Nutrition(N). P-Full Professor, AP-Associate Professor, SL-Senior Lecturer, L-Lecturer. 1-POC, 2-APG, 3-SLA, 4-SLM, 5-SLAG, 6-PE, 7-PE, 8-LA, 9-LA, 10-PA, 11-SLA, 12LA, 13-APPL, 14-LPL, 15-SLMB, 16-APMB, 17-P-MB, 18-LMB, 19-APN.

Table 1. Comparison of the number of citations using Google Scholar between various faculty members in Tel-Hai Academic College from 2004 to 2014. There are significant differences between professors and senior lecturers according to the F-test $(P<0.05)$, however the number of citation papers by lecturers was significantly higher than by senior lecturers according to the F-test.

\begin{tabular}{|c|c|c|c|c|c|c|c|c|c|c|c|c|}
\hline Years & & 2004 & 2005 & 2006 & 2007 & 2008 & 2009 & 1010 & 2011 & 2012 & 2013 & 2014 \\
\hline Animal Science & Professor & 95 & 89 & 85 & 143 & 129 & 142 & 129 & 170 & 133 & 199 & 183 \\
\hline $\begin{array}{l}\text { Environment } \\
\text { Science }\end{array}$ & Professor & 113 & 88 & 117 & 96 & 122 & 104 & 122 & 123 & 135 & 139 & 154 \\
\hline $\begin{array}{c}\text { Animal } \\
\text { Physiology }\end{array}$ & Senior Lecture & & & 2 & 7 & 7 & 13 & 19 & 40 & 66 & 89 & 78 \\
\hline $\begin{array}{l}\text { Plant Fungi } \\
\text { Disease }\end{array}$ & Lecture & 2 & & 13 & 13 & 17 & 20 & 17 & 13 & 17 & 31 & 38 \\
\hline $\begin{array}{c}\text { Animal } \\
\text { Plant Interaction }\end{array}$ & Senior Lecture & 1 & 2 & 1 & 5 & 11 & 7 & 6 & 2 & 13 & 12 & 14 \\
\hline Censer Research & Senior Lecture & 10 & 30 & 34 & 47 & 74 & 75 & 106 & 138 & 137 & 114 & 137 \\
\hline Economy & Professor & 13 & 25 & 35 & 27 & 46 & 26 & 48 & 41 & 47 & 52 & 74 \\
\hline
\end{tabular}

universities [1]. However, the previous study examined different parameters, the number of publications (RG and AM), the number of citations (RG and AM), and impact factors (RG and AM) belonging only to full professors [3]-[5]. The current study examined publication downloads by all degrees of faculty members from Tel-Hai Academic College. The study (using RG and GS) found that the number of citations downloaded by professors from Tel-Hai Academic College was higher than the number downloaded by faculty members at lower degrees (lecturers and senior lecturers). The contribution of the current study shows that differences exist between the two parameters(RG and GS), and that there is a lesser effect by the number of publications and the degree of faculty members compared to the number of citations, which are highly affected by these parameters. Gasses et al. (1997) [3] developed standards that could guide the documentation and evaluation of faculty scholarship. The current study suggested adding downloads data available on the Internet (RG and GS) using both citations [1] and download papers published, in order to improve the evaluation of scientific work by faculty members. In the current study, data are collected only from the Internet, representing information that is available to everyone (RG and GS). Differences exist between RG and GS as well as other Internet sites, e.g., Microsoft Academic (MA) (not used in this study, which might provide more significant information than RG and GS). In all the various Internet sites (RG, GS and MA), the highest value in most parameters examined in Tel-Hai Academic College was for professors from the area of Animal Science [3]-[6]. In summary, the results of the current study and previous results show that different parameters can be used in evaluating faculty members. The parameter of the number of publication downloads might show the relevance of publications during the pe- 
riod examined, while other parameters such as the number of citations might emphasize other evaluation parameters; however, all of the parameters are important. Moreover, although the relative evaluations among faculty members are very similar, it is advisable to use more than one Internet site to compare between faculty members.

\section{References}

[1] Centra, J.A. (1997) How Universities Evaluate Faculty Performance: A Survey of Department Heads. GRE Board Research Report GREB 75-5bR, 75, 1-26.

[2] Degani, G. (2015) Academic Status of Full Professors in the Faculty of Science and Technology at the Tel-Hai Academic College and the MIGAL_-Galilee Research Institute Compared to the Academic Status of Full Professors in the Same Field in Research Universities in Israel. World. Op. J. Educat. Res., 2, 1-8.

[3] Glasses, C.E.H., Huber, M.T. and Maeroff G.I. (1997) Scholarship Assessed: Evaluation of the Professoriate. Special Report, ERIC, 1-130.

[4] Network-Research Gate. www.researchgate.net/profile/

[5] Network-Google Scholar. http://scholar.google.co.il//

[6] Network. https://www.google.co.il/\#q=Network-Academic.research.microsoft.com 